\title{
FIFTH EURASIA CONFERENCE ON CHEMICAL SCIENCES
}

The 5th Eurasia Conference on Chemical Sciences will be held in Guangzhou (Canton), P. R. China, on 10-14 December 1996. This conference will bring scientists from the Eurasia Supercontinent together for the further enhancement of scientific cooperation and development in the field of chemical research.

The scientific sessions will include the following topics:

Solution coordination chemistry.

Environmental and analytical chemistry.

Bioremediation.

Rare-earth (bio)coordination chemistry.

Toxicology of metal ions.

Nanochemistry

Supramolecular chemistry and materials

Theoretical, computational and modeling chemistry

Chemistry of traditional drugs

Regulation of biosystems by metal ions and small molecules

Biopolymers and biomimetic polymers

The deadline for submission of abstracts is May 1, 1996. A 1-page camera-ready manuscript, that will be published in the Proceedings of the Conference, will be required from participants wishing to present a poster or an oral communication.

Registration fees for the conference will cover the payments of the participation in all the scientific sessions, the proceedings and all printed materials of the conference, the shuttles between airport or railway station and hotels, a welcome reception, a banquet and other scheduled social events including one day excursion to outer suburban or inner city. Cost of registration will be US $\$ 300$.

Various categories of hotel rooms will be available. Special events and tours will be organized. Opportunities for sightseeing and tours will be provided for attendees and their spouses.

\section{International Organizing Committee:}

Jan Reedijk (Chairman),

Ivano Bertini,

Mu Shik Jhon,

Hitoshi Ohtaki,

B. Michael Rode,

A. Geoff. Sikes,

John Webb,

Salag Dhabanandana,

Youngkyu Do.

\author{
All inquiries relating to the conference should be addressed to: \\ Prof. Liang-Nian Ji \\ General Secretary EuAsC2S-1996 \\ Biotechnology Research Center \\ Zhongshan( Sun Yatsen) University \\ Guangzhou (Canton) 510275, P. R. China
}

Tel: 86204185461 or 418663007115

Fax: 86204189173 or 86204185551

e-mail: Leiy@ bepc2.ihep.ac.cn 